\title{
Jallo Jack, Vaccaro Alexander R (eds): Neurotrauma and critical care of the spine
}

\author{
2009, Hardcover, 260 pp, 130 figs, $€$ (D) 129.95 CHF 216.00, ISBN 978-1-604-06033-1
}

\author{
Pierre Kehr
}

Received: 16 August 2009 / Accepted: 18 August 2009 / Published online: 30 August 2009

(C) Springer-Verlag 2009

This book is the most useful summary of present knowledge about epidemiology, pathophysiology, assessment and management of spinal cord injuries today.

The reader will also find an update about the concepts and strategies regarding spinal cord regeneration, and a well-illustrated overview of spinal biomechanics.

The different types of spinal injury classification systems are listed and explained with summarizing tables and drawings, supported by some important pictures in the imaging chapters, which includes tables with injury type, cause, characteristics and corresponding best or recommended imaging modality.

The main part of the book is dedicated to the management: From the pre-hospital phase, followed by the acute hospital care, discussing timing of surgery and specifities concerning the management of cervical, cervicothoracic, and thoracolumbar injuries. Treatment algorithms are proposed and different examples with instrumentation shown.

A special section is dedicated to SCI in the athlete: Different injury syndromes following various sportive activities, their evaluation and management, and finally the recommendations for "return to play" after less severe trauma are listed.
The "critical care" chapter reminds the main general complications that may occur and recalls the essential pharmacological agents used in ICU.

Paediatric spinal injuries are dealt with in a special chapter, including summarizing tables and some illustrative cases, which deserve a special credit.

Finally, the socioeconomic aspects and the rehabilitation and recovery from spinal injuries are discussed. Again the reader will find tables and the mostly used scales. The ethical considerations in the last chapter about quality of life and professionalism are the final point of this holistic overview of a difficult subject of spinal neurotrauma.

It is a great book that deserves a widespread distribution among spine surgeons and physicians involved in the treatment of spinal injuries. Moreover, some chapters can also be recommended to non-specialists and medical students.

No funds were received in support of this study.

Denis L. Kaech Chur
P. Kehr ( $($ )

Strasbourg, France

e-mail: kehrpier@aol.com 